\title{
Extreme Waves and Rayleigh Distribution in the South Atlantic Ocean Near the Northeast Coast of Brazil
}

\author{
Paul C. Liu ${ }^{*}, 1$ and Uggo F. Pinho ${ }^{2}$ \\ ${ }^{I}$ NOAA Great Lakes Environmental Research Laboratory, Ann Arbor, MI, USA \\ ${ }^{2}$ Petrobras, Rodovia Amaral, Peixoto, RJ, Brazil
}

\begin{abstract}
In this brief communication we present the first result on what have we learned from a long, virtually continuously recorded wave height data set. The data was recorded by Petrobras on a mobile platform located on the northeast Brazilian coast. We found the well-known Rayleigh relation, $H_{\max } / H_{s}=[\ln (N) / 2]^{1 / 2}$, fits the data real well for $\mathrm{H}_{\max } / \mathrm{H}_{\mathrm{s}}$ up to about 2.2, but diverges distinctly when $\mathrm{H}_{\max } / \mathrm{H}_{\mathrm{s}}$ values grow larger. An empirical relation for larger $\mathrm{H}_{\max } / \mathrm{H}_{\mathrm{s}}$ can be empirically represented by $\mathrm{H}_{\max } / \mathrm{H}_{\mathrm{s}}=\left[\ln \left(\mathrm{N}^{2}\right) / 2\right]^{1 / 4}$.
\end{abstract}

Keywords: Waves, Extreme waves, Rayleigh distribution, South Atlantic Ocean, Northeast coast of Brazil, Empirical studies.

\section{INTRODUCTION}

For over six decades, conventional ocean wave measurements have been traditionally and typically recorded for only 20 minutes every hour or every few hours. This conceptually simple practice has been persisted for all these years even through advancement in technology have grown leaps and bounds, especially since the last part of the 20th century. Recently however, Petrobras, an multinational energy company, has implemented a new system on their oil platforms where waves are measured continuously. These new recordings have provided not only new data, but have also provided us a new perspective in wave analysis and understanding. In this paper, our main goal is to examine one of these unique, unprecedented new Petrobras data sets that have provided us with some exciting new insight.

\section{THE STUDY AREA}

The Petrobras platforms are jack-up rig type mobile platforms located on the northeast Brazilian coast at the continental shelf in the South Atlantic Ocean as shown in Fig. (1). The dominant wind in this region comes from the southeast and east quadrant, and the wave climate is mainly governed by winds with swells arriving from the Northern hemisphere.

\section{THE INSTRUMENTATION}

Wave data were measured with a Miros Range Finder manufactured by Miros AV of Norway. The Miros Range Finder is an accurate sensor for measuring distance to the water surface. The continuous zero up-crossing wave height data used in this paper were obtained from a time series recorded at a $2 \mathrm{~Hz}$ sampling frequency. There were only a few minuscule breaks or interruptions in the data set. The

*Address correspondence to this author at the NOAA/Great Lakes Environmental Research Laboratory, NOAA/GLERL, USA; Tel: (734)7412294; Fax: (734)741-2055; E-mail: paul.c.liu@noaa.gov

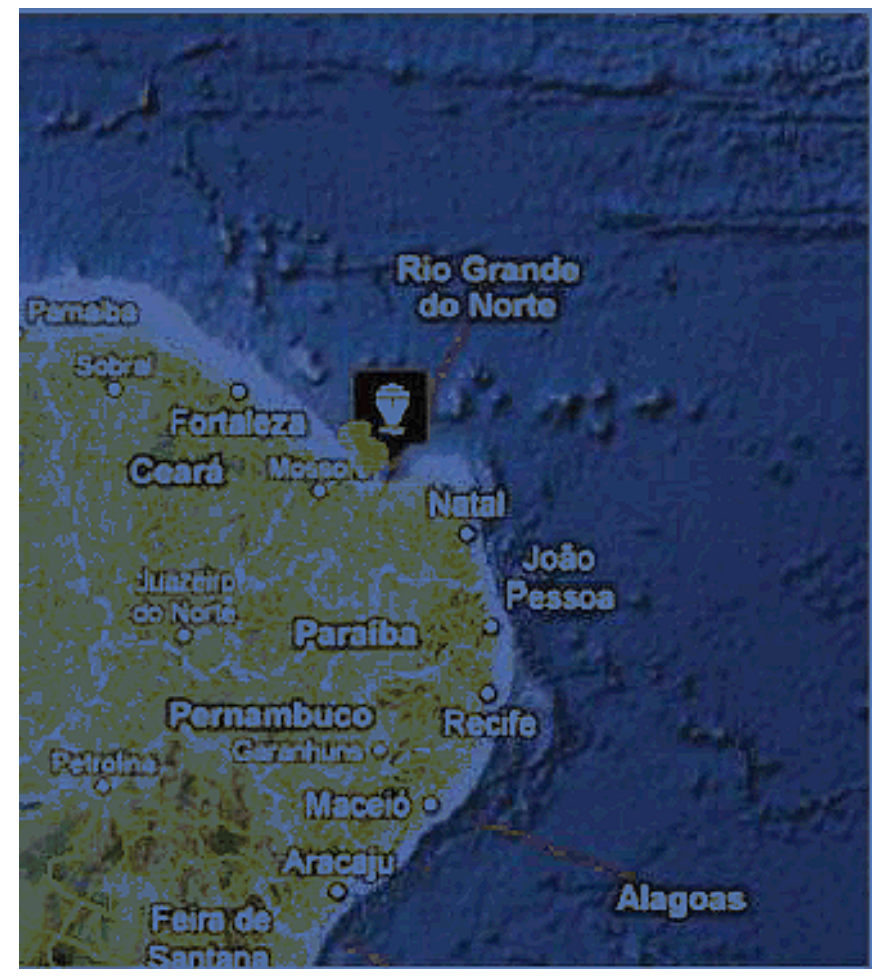

Fig. (1). Map showing the general location of the recording platform.

metocean platform, where the Miros Range Finder was installed, was moved once during the operation, in August 2010 , to a nearby location about $10 \mathrm{~km}$ away as shown in Fig. (2). This move caused a one-day gap in the data set. We examined the data separately both before and after the move and then combined them into one large data set.

\section{THE DATA ANALYSIS}

The switch from the conventional wave data analysis methods, which have been used for over six decades using 20-minute data sets [1], to the new data analysis methods 


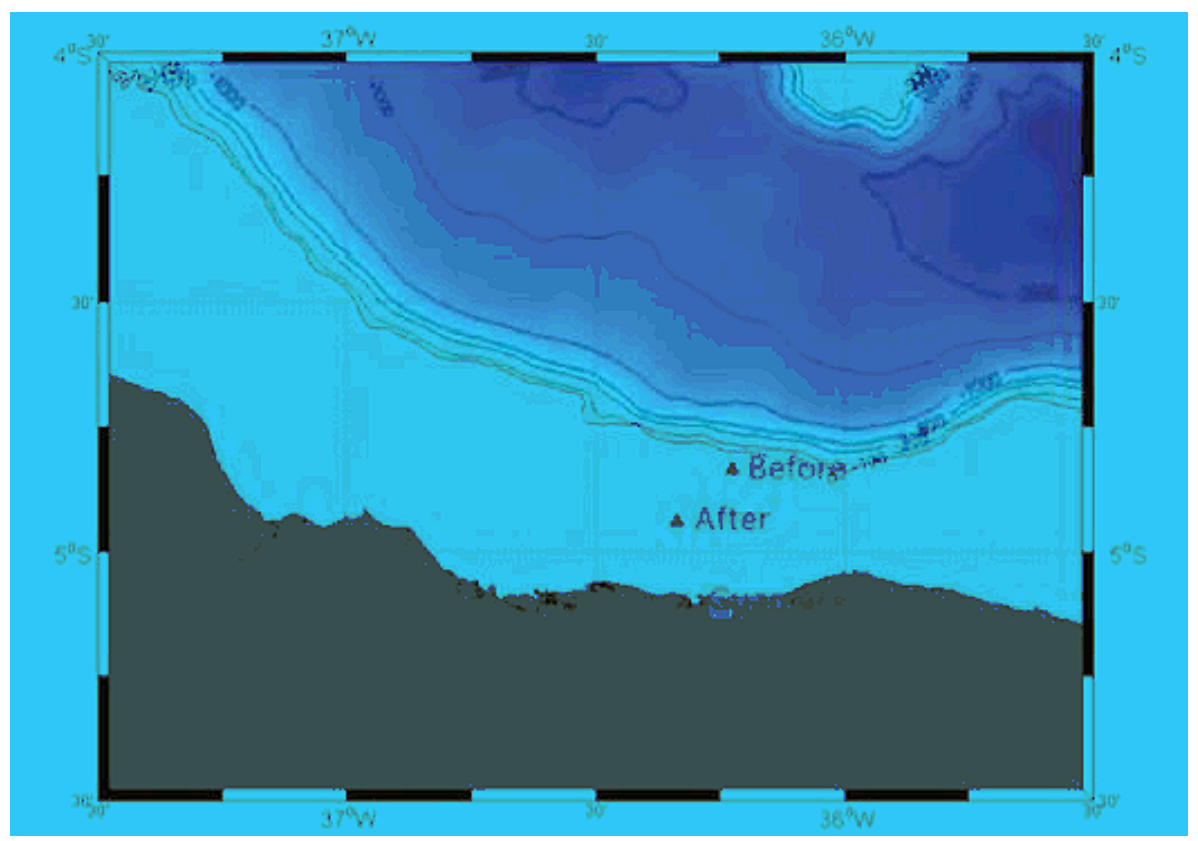

Fig. (2). Closer view of locations of the platform offshore from Guamare. The "Before" and "After" are the same platform as it was operated during April 15,2010 - August 7, 2010 and August 8,2010 - February 2, 2011 respectively with a brief one day gap while the recording was continuing.

using continuous, basically non-interrupted wave measurement is not an inconsequential step. It means an immediate 3 orders of magnitude increase in the quantity of data. It also represents a major leap conceptually that casts off familiar postulates such as stationarity in wave data. These new data sets can potentially unleash new opportunity and innovation in wave data analysis.

We chose not to use conventional analysis approaches on these new data sets. One immediate notion that came to mind was to use the well-known Rayleigh relation based on the Rayleigh distribution [2]:

$\mathrm{P}\left(\mathrm{H}>=\mathrm{H}_{\max }\right)=1 / \mathrm{N}=\exp \left[-\left(2 \mathrm{H}^{2} / \mathrm{H}_{\mathrm{s}}^{2}\right)\right]$,

That leads to

$\mathrm{H}_{\max } / \mathrm{H}_{\mathrm{s}}=[\ln (\mathrm{N}) / 2]^{1 / 2}$, which relates the ratio of maximum wave height, $\mathrm{H}_{\max }$, to significant wave height, $\mathrm{H}_{\mathrm{s}}$, to the number $\mathrm{N}$ in a group of $\mathrm{N}$ consecutive wave heights, which is the basis that has been widely used to estimate how many waves one needs to observe in order to obtain a given extreme value of $\mathrm{H}_{\max }$ in terms of $\mathrm{H}_{\mathrm{s}}$.

Based on this Rayleigh relation, larger ratios of $\mathrm{H}_{\max } / \mathrm{H}_{\mathrm{s}}$ such as 3,4 , or 5 , can be expected, but it requires $\mathrm{N}$ to be $6.6 \times 10^{7}, 7.9 \times 10^{13}$, or $5.2 \times 10^{21}$ respectively as the numbers of waves needed for the ratios to occur. These are extremely large numbers, which can translate into millions of years for the large ratios to happen - rather unrealistic, but we have no way to adjust or verify. Now, however, with the recorded 4.6 million consecutive zero-upcrossing wave heights obtained so far, we can at least begin to attempt a realistic view on

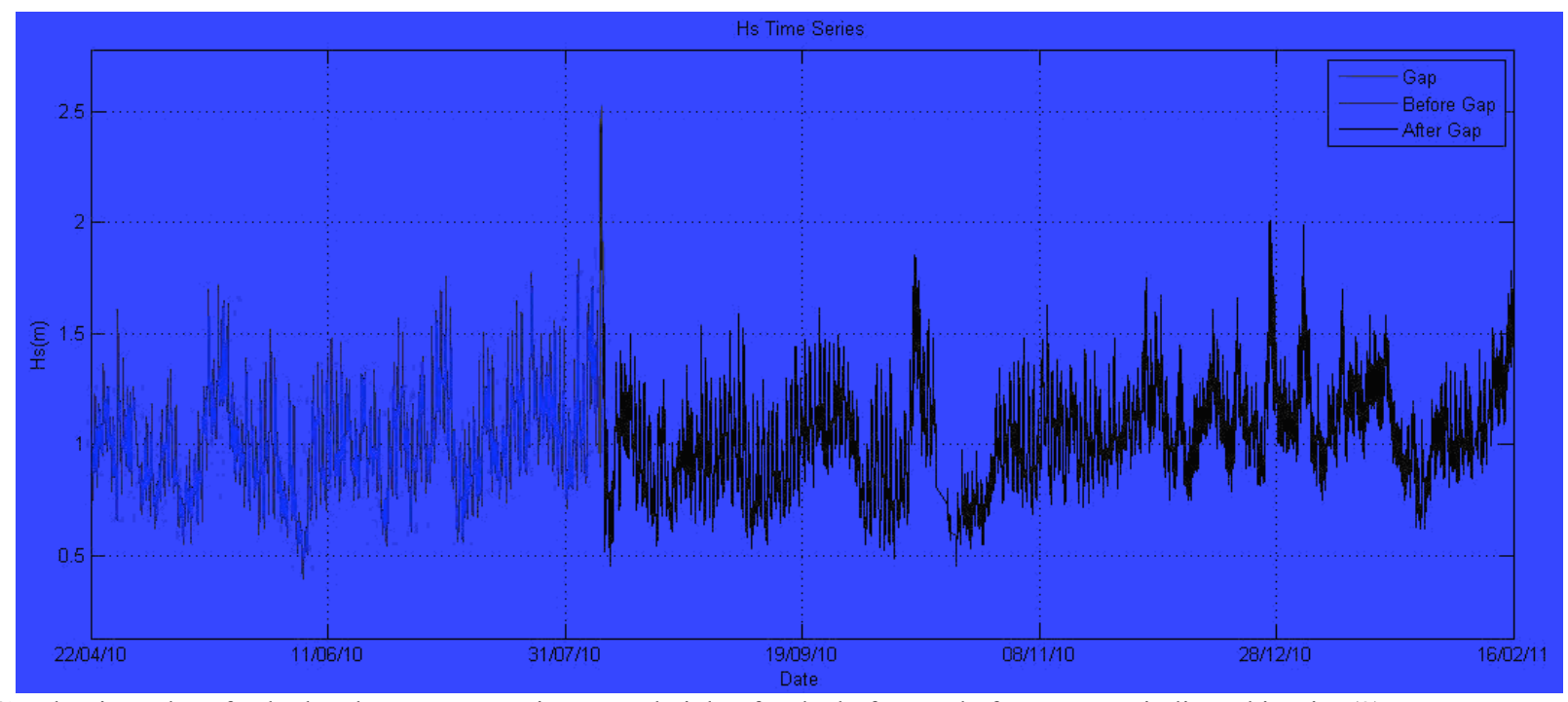

Fig. (3). The time plot of calculated zero-up-crossing wave heights for the before and after cases as indicated in Fig. (2). 


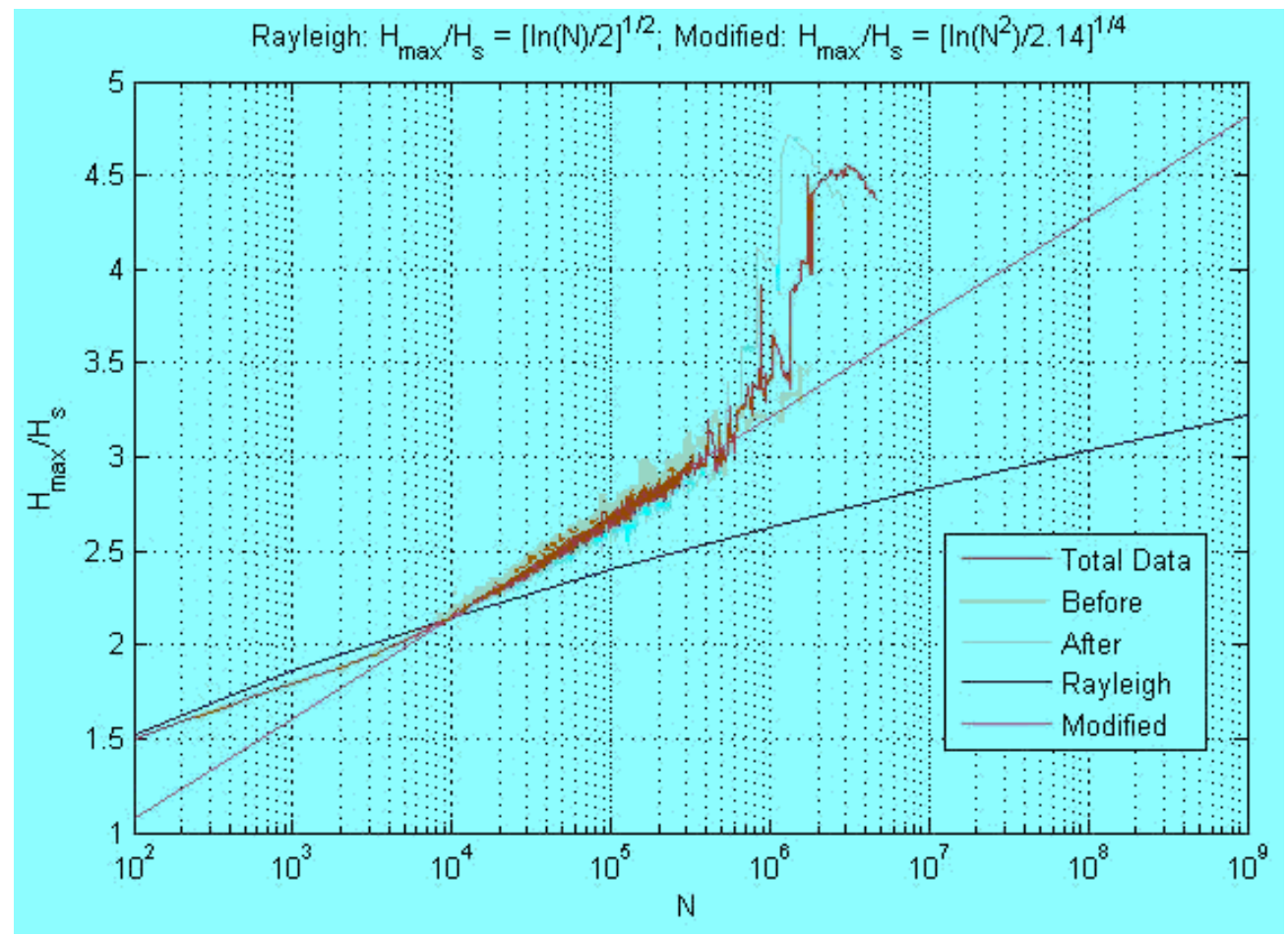

Fig. (4). Main results of correlating $\mathrm{H}_{\max } / \mathrm{H}_{\mathrm{s}}$ with number of waves $\mathrm{N}$ and comparing with the long-standing Rayleigh relation along with a proposed modified empirical relation.

this well-known and never-before substantiated Rayleigh relation, Eq. (2).

\section{RESULTS}

Fig. (3) presents a time plot of the continuously recorded over 4.6 million zero-up-crossing wave heights. As mentioned before, data was recorded on the same jack-up type Petrobras platform that was later moved to a nearby station, with a one-day gap in between. Because the move was only about $10 \mathrm{~km}$ away, we feel it is justifiable to consider the data sets before and after the move as one single data set.

Fig. (4) presents the main results that we expected: a correlation of $\mathrm{H}_{\max } / \mathrm{H}_{\mathrm{s}}$ with their corresponding available number of zero-up-crossing wave heights, $\mathrm{N}$, with the theoretical Rayleigh relation plotted as the blue line. This result can be considered as unprecedented, because for the first time, we have been able to obtain fairly large numbers of $\mathrm{N}$ for this task. The following are some details and observations:

1. With an availability of over 4 million N's, we were able to gather various combinations of N's, specifically every segment from 100 to over 4 million at 100 increments to correlate each segment with their corresponding $\mathrm{H}_{\max } / \mathrm{H}_{\mathrm{s}}$ data as shown by the yellow, green, and red curves in the figure for the before the data gap, after the data gap, and the total data, respectively. For every selected number of $\mathrm{N}$ data, there is always $\mathrm{H}_{\max }$, but it is not immediately clear what should be the significant wave height $\mathrm{H}_{\mathrm{s}}$ for the segment? We are only familiar with conventional $\mathrm{H}_{\mathrm{s}}$ that are generally obtained from a 20 -minute data set. So how to get a $\mathrm{H}_{\mathrm{s}}$ value for large number of N's?
Since there is no precedent on a study like this one and without any available clear guidance, we have decided to follow the basic definition of significant wave heights, namely using the average of the highest one third data in the segment no matter how large the number of $\mathrm{N}$ might be. This seems to work well. There is really no reason to expect that the definition of "averaging the highest one third data" should only be applicable to the 20-minute cases. Perhaps the only possible concern is that for larger number of N's the assumption of stationary may no longer hold. But a stationary assumption is clearly much too unrealistic for the real ocean process at any means.

2. While we would generally expect that the more data the better, it appears that the cases of before and after the gap and the total data all tend to manifest toward a single, well defined empirical relation that reasonably follows the Rayleigh relation below $\mathrm{N}=10^{4}$, but conspicuously diverges from the Rayleigh relation beyond that. There's some uncertainty at the high end of the data set for the N's greater than $10^{6}$ that probably can only be settled with more data. Nevertheless, the results have provided us with an unprecedented view of a robust data set giving rise to a well-behaved empirical relation.

3. As the data correlates well, just by visual observation, with the Rayleigh relation for $\mathrm{N}$ values up to $10^{4}$ and $\mathrm{H}_{\max } / \mathrm{H}_{\mathrm{s}}<2.2$, it clearly justifies the conventional notion that Rayleigh distribution prevails for regular wave conditions. Concurrently, the other widely accepted consideration that freaque waves usually occur for $\mathrm{H}_{\max } / \mathrm{H}_{\mathrm{s}}>2.2$, is also readily implied. 
4. However other than with the $\mathrm{H}_{\max } / \mathrm{H}_{\mathrm{s}}>2.2$ implication of freaque wave occurrences, we really did not have any idea what might happen other than to rely on the Rayleigh relation in general in these cases. Now with the results shown in Fig. (4) we can expect those $\mathrm{H}_{\max } / \mathrm{H}_{\mathrm{s}}$ larger than 2.2 cases to happen for much less $\mathrm{N}$ numbers than Rayleigh relation dictates. As a matter of fact, analogous to the Rayleigh relation in Eq. (2), we have found a modified relation to fit the main part of our data quite well:

$\mathrm{H}_{\max } / \mathrm{H}_{\mathrm{s}}=\left[\ln \left(\mathrm{N}^{2}\right) / 2.15\right]^{1 / 4}$

Thus, we propose using the Rayleigh relation Eq. (2) when $\mathrm{H}_{\max } / \mathrm{H}_{\mathrm{s}}$ is less than 2.2, but using the modified relation Eq. (3) for $\mathrm{H}_{\max } / \mathrm{H}_{\mathrm{s}}$ greater than 2.2. The cases that would lead to significantly lesser $\mathrm{N}$ numbers than Rayleigh relation indicates are expected to occur for larger $\mathrm{H}_{\max } / \mathrm{H}_{\mathrm{s}}$ cases which is intuitively plausible at any rate.

\section{CONCLUDING REMARK}

The wheel of conceptual advancement turns rather slowly. Still, moving away from conventional 20-minute discrete recordings after over six decades is an encouraging step in the right direction. Of course, the worst thing that can happen is not recognizing this step as a conceptual advance- ment and treating the additional data as merely additional 20 minutes of data and continuing with the same analysis techniques. At any rate, we hope this effort that elucidated the extent of applicability of conventional Rayleigh distribution can encourage further use of non-conventional analysis and thereby stimulate further novel approaches in future ocean wave studies.

\section{CONFLICT OF INTEREST}

None declared.

\section{ACKNOWLEDGEMENT}

We wish to sincerely thank the management of Petrobras for the privilege of using their newly recorded data for this interesting, novel study. We wish also to thank the referee for the constructive comments. This is GLERL Contribution No. 1608 .

\section{REFERENCES}

[1] Barber NF. Water Waves, Wykeham Publications, London. 1969.

[2] Longuet-Higgins MS. On the statistical distribution of the heights of sea waves. J Mar Res 1952; 11(3): 345-66. 